\title{
De betekenis van een op actuele waarde geba- seerd winstbegrip bij inflatie
}

\section{Inleiding}

In dit artikel wordt ingegaan op de vraag of de toepassing van actuele waarden' in de jaarrekening een goede methode oplevert om de effecten van inflatie op de desbetreffende jaarrekening weer te geven. Teneinde deze vraag te kunnen beantwoorden dient eerst te worden aangegeven welke doelstelling wij kiezen met betrekking tot de jaarrekening. Wij richten ons hierbij op de externe verslaggeving. De invloed van actuele waarden in het kader van de interne verslaggeving is uitgebreid aan de orde gekomen in een door het Maandblad voor Accountancy en Bedrijfshuishoudkunde georganiseerde workshop. Voor de resultaten van deze workshop zie: J. Klaassen en P. Verburg 1984 .

Bij de externe verslaggeving ligt het accent op het verstrekken van informatie aan belanghebbenden. Bij deze informatieverstrekking staat centraal het geven van inzicht in de financiële positie van de desbetreffende onderneming. De winstgevendheid van het geïnvesteerde vermogen speelt bij het beoordelen van deze financiële positie een belangrijke rol. De probleemstelling van dit artikel zal derhalve betrekking hebben op de vraag of met behulp van een op actuele waarde gebaseerd winstbegrip een inzicht kan worden verkregen in de winstgevendheid van het geïnvesteerde vermogen in tijden van inflatie en zo ja op welke wijze deze op actuele waarde gebaseerde winst dan dient te worden berekend.

De winst voor jaar $t$ wordt niet rechtstreeks beïnvloed door de in dat jaar opgetreden inflatie. Dit is wel het geval bij de door middel van het in de onderneming geïnvesteerde vermogen te genereren cash flows voor de jaren $t$ $\mathrm{t} / \mathrm{m} \mathrm{n}$, welke cash flows direct dan wel indirect - afhankelijk van het gekozen toerekeningssysteem - de winst voor jaar $t$ bepalen. In paragraaf 2 zal nader worden ingegaan op het verband tussen de winst voor jaar $t$ en de cash flows voor de jaren $t \mathrm{t} / \mathrm{m} \mathrm{n}$ in een stituatie zonder inflatie bij twee op verschillende toerekeningssystemen gebaseerde winstbegrippen, namelijk het administratieve - op registratieregels gebaseerde - winstbegrip (accounting income) en het economische winstbegrip (economic income). 
Vervolgens zal in paragraaf 3 worden aangegeven op welke wijze de winst voor jaar $t$ kan worden gecorrigeerd, teneinde de invloed van de in jaar $t$ opgetreden inflatie op de cash flows voor de jaren $t \mathrm{t} / \mathrm{m} \mathrm{n}$ in deze winst te verwerken. Wij baseren ons daarbij op de administratieve winst, aangezien de op actuele waarde berekende winst op hetzelfde toerekeningssysteem is gebaseerd als deze administratieve winst. Vervolgens wordt in paragraaf 4 deze gecorrigeerde nominale resp. reële winst voor jaar $t$ vergeleken met de op basis van actuele waarde vastgestelde winst voor jaar $t$. Laatstgenoemde winst wordt zodanig berekend dat de totale in jaar $t$ gerealiseerde herwaardering $^{2}$ buiten de winstberekening voor jaar $\mathrm{t}$ blijft.

Bij de uitwerking van de in alinea twee aangegeven probleemstelling wordt geabstraheerd van de invloed van het financieren met vreemd vermogen en van het investeren in monetaire activa, alsmede van de invloed van de winstbelasting. Deze aspecten zullen in een tweede artikel aan de orde komen. ${ }^{3}$ Ten slotte gaan wij er eenvoudigheidshalve vanuit dat het vermogen alleen in materiële vaste activa is geïnvesteerd. ${ }^{4}$

\section{De relatie tussen de winst voor jaar $t$ en de cash flows voor de jaren $\mathbf{t} \mathbf{t} / \mathbf{m} \mathbf{n}$ in een situatie zonder inflatie}

Algemeen kan worden gesteld dat de met het in een project c.q. in de onderneming geïnvesteerde vermogen ${ }^{5}$ te realiseren resp. gerealiseerde winst over de gehele levensduur bezien gelijk is aan de som van de door middel van dit geïnvesteerde vermogen te genereren resp. gegenereerde cash flows verminderd met de investeringsuitgave(n). De winst voor jaar $t$ wordt bepaald door de cash flows voor de jaren $t \mathrm{t} / \mathrm{m} \mathrm{n}$ en door het systeem waarmee de over de gehele levensduur te realiseren resp. gerealiseerde winst wordt toegerekend aan de opeenvolgende jaren. Wij zullen het verband tussen de winst voor jaar $t$ en de cash flows voor de jaren $t \mathrm{t} / \mathrm{m} n$ nader toelichten bij twee op verschillende toerekeningssystemen gebaseerde winstbegrippen, namelijk het administratieve - op registratieregels gebaseerde - winstbegrip (accounting income) en het economische winstbegrip (economic income). Wij gaan hierbij uit van een situatie zonder inflatie.

De essentie van het administratieve winstbegrip ligt in de toerekening van ontvangsten en uitgaven aan een periode. Het systeem van toerekening bepaalt gegeven de cash flow voor jaar $t$ de hoogte van de winst voor jaar $t$. Deze toerekening ${ }^{6}$, die onder meer tot uitdrukking komt in het gehanteerde afschrijvingssysteem, bepaalt in principe tevens de boekwaarde van de materiële vaste activa waarin het vermogen is geïnvesteerd per het einde van jaar $\mathrm{t}\left(=\mathrm{B}^{\circ}(\mathrm{t})\right)$.

Bij het economische winstbegrip bepaalt onder de in de inleiding genoemde veronderstellingen de aan de materiële vaste activa toe te kennen waarde de hoogte van de jaarlijkse winst. De waarde van deze activa per het einde van jaar $t\left(=V^{\circ}(t)\right.$ resp. $\left.V(t)\right)$ wordt bepaald door de op tijdstip 0 resp. $t$ begrote - door middel van het in deze activa geïnvesteerde vermogen te genereren - 
cash flows voor de jaren $t+1 \mathrm{t} / \mathrm{m} \mathrm{n}$ contant te maken met behulp van een extern bepaalde disconteringsvoet, veelal de rendementseis van de vermogensverschaffers.

Wij lichten beide genoemde winstbegrippen aan de hand van een eenvoudig voorbeeld nader toe. Hierbij zullen wij eerst ingaan op de op tijdstip 0 voor jaar $\mathrm{t}$ begrote administratieve winst $\left(=\mathrm{E}^{\circ}(\mathrm{t})\right)$ resp. economische winst (= $\mathrm{EI}^{\circ}(\mathrm{t})$ ) en vervolgens op de in jaar $\mathrm{t}$ gerealiseerde administratieve winst $(=\mathrm{E}(\mathrm{t}))$ resp. economische winst $(=\mathrm{EI}(\mathrm{t}))$.

Onder de aanvullende veronderstellingen dat:

- de investeringsuitgave (=I) plaatsvindt aan het begin van jaar 1 (= tijdstip O);

- de door middel van de investering te genereren cash flows ${ }^{7}\left(=\mathrm{CF}^{\circ}(\mathrm{t})\right)$ vrijvallen aan het einde van elk jaar;

- deze cash flows geheel worden uitgekeerd aan de vermogensverschaffers,

kunnen de relaties voor de begrote administratieve en economische winst voor jaar $t$, alsmede de relaties voor de op deze winsten gebaseerde rendementen als volgt worden weergegeven:

$$
\begin{aligned}
& E^{\circ}(t)=C^{\circ}(t)-A^{\circ}(t)=C F^{\circ}(t)+B^{\circ}(t)-B^{\circ}(t-1) \\
& r^{\circ}{ }_{t}=E^{\circ}(t): B^{\circ}(t-1)
\end{aligned}
$$

$$
\text { waarbij } \begin{aligned}
\mathrm{B}^{\circ}(\mathrm{O}) & =\mathrm{I} ; \\
\mathrm{B}^{\circ}(\mathrm{t}) & =\mathrm{B}^{\circ}(\mathrm{t}-1)-\mathrm{A}^{\circ}(\mathrm{t}) ; \\
\mathrm{A}^{\circ}(\mathrm{t}) & =\text { de voor een situatie zonder inflatie vastgestelde afschrij- } \\
& \text { ving voor jaar } \mathrm{t} ; \\
\mathrm{r}^{\circ} \mathrm{t} & =\text { het begrote administratieve rendement voor jaar } \mathrm{t} .
\end{aligned}
$$

$$
\begin{array}{ll}
\mathrm{EI}^{\circ}(\mathrm{O})=\mathrm{V}^{\circ}(\mathrm{O})-\mathrm{I} & \\
\mathrm{EI}^{\circ}(\mathrm{t})=\mathrm{CF}^{\circ}(\mathrm{t})+\mathrm{V}^{\circ}(\mathrm{t})-\mathrm{V}^{\circ}(\mathrm{t}-1) & (\text { voor } \mathrm{t}=1 \mathrm{t} / \mathrm{m} \mathrm{n}) \\
\mathrm{r}(\mathrm{EI})^{\circ} \mathrm{t}=\mathrm{EI}^{\circ}(\mathrm{t}): \mathrm{V}^{\circ}(\mathrm{t}-1)=\mathrm{k}^{\circ} & (\text { voor } \mathrm{t}=1 \mathrm{t} / \mathrm{m} \mathrm{n})
\end{array}
$$

$$
\begin{aligned}
\text { waarbij } \mathrm{V}^{\circ}(\mathrm{t})= & \sum_{j=1}^{\mathrm{n}-\mathrm{t}} \frac{\mathrm{CF}^{\circ}(\mathrm{j}+\mathrm{t})}{\left(1+\mathrm{k}^{\circ}\right) \mathrm{j}} \\
\mathrm{r}(\mathrm{EI})^{\circ} \mathrm{t}= & \text { het begrote economische rendement voor jaar } \mathrm{t} ; \\
\mathrm{k}^{\circ} & \text { de voor een situatie zonder inflatie begrote rendements- } \\
& \text { eis van de vermogensverschaffers voor de jaren } 1 \\
& \mathrm{t} / \mathrm{m} \mathrm{n} .
\end{aligned}
$$




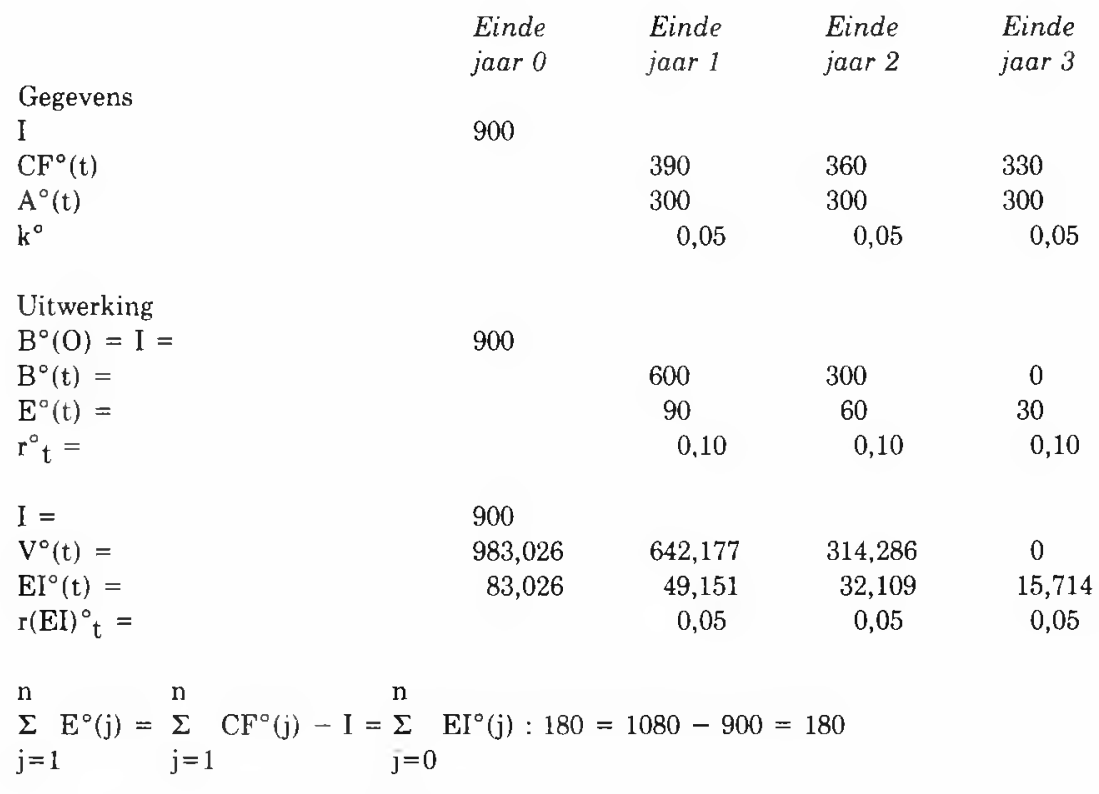

Wij zullen thans aan de hand van dit voorbeeld ingaan op de relatie tussen de begrote winst voor jaar $t$ en de begrote cash flows voor de jaren $t / \mathrm{m} n$ in een situatie zonder inflatie. Dit is bij het economische winstbegrip eenvoudig, aangezien dit winstbegrip reeds is gedefinieerd als een cash flow relatie (zie de vergelijkingen 4 en 6 ).

Toegepast op het voorbeeld betekent dit dat de begrote economische winst voor jaar 2 kan worden weergegeven als:

$$
\begin{aligned}
\mathrm{EI}^{\circ}(2)=360+ & \stackrel{330}{\left(\frac{360}{1,05}\right)}-\left(\frac{360}{1,05}+\frac{330}{1,05^{2}}\right)= \\
& =360+314,286-642,177=32,109
\end{aligned}
$$

De schakel tussen deze begrote winst voor jaar t en de begrote cash flows voor de jaren $\mathrm{t} t / \mathrm{m} n$ wordt - onder de genoemde veronderstellingen - gevormd door de waarde van de materiële vaste activa waarin het vermogen is geinvesteerd per het einde van jaar $t$ resp. per het einde van jaar $t-1$, welke waarde dus is gedefinieerd als een cash flow relatie.

Ook bij de administratieve winst kan de boekwaarde van de materiële vaste activa waarin het vermogen is geinvesteerd en daarmee tevens deze winst in de vorm van een cash flow relatie worden weergegeven. De disconteringsvoet is nu echter niet een extern bepaalde grootheid (bijvoorbeeld de rendementseis van de vermogensverschaffers), doch is voor jaar $t$ (voor $t=1 \mathrm{t} / \mathrm{m} \mathrm{n}$ ) gelijk aan het - door middel van het gehanteerde afschrijvingssysteem en de be- 
grote cash flow voor jaar $\mathrm{t}$ - berekende rendement voor het desbetreffende jaar.

$$
B^{\circ}(t)=\sum_{j=1}^{n-t} \frac{C F^{\circ}(j+t)}{\mathfrak{j}_{M\left(1+r^{\circ} k+t\right)}}
$$

Voor de afleiding van deze relatie wordt verwezen naar het in noot 3 genoemde research memorandum.

Toegepast op het voorbeeld betekent dit dat de begrote administratieve winst voor jaar 2 kan worden weergegeven als:

$$
\begin{aligned}
\mathrm{E}^{\circ}(2) & =360+\left(\frac{330}{1,10}\right)-\left(\frac{360}{1,10}+\frac{330}{1,10^{2}}\right)= \\
& =360+300-600=60
\end{aligned}
$$

Tot slot zullen wij ingaan op de relatie die kan worden gelegd tussen de in jaar $t$ gerealiseerde winst en de op tijdstip $t$ begrote cash flows voor de jaren $\mathrm{t}+1 \mathrm{t} / \mathrm{m} \mathrm{n}$.

Zoals vermeld wordt bij het economische winstbegrip de op tijdstip $t$ aan de materiële vaste activa toe te kennen waarde gewijzigd, indien er wijzigingen optreden ten aanzien van de voor de toekomstige jaren begrote cash flows en/ of in de begrote rendementseis van de vermogensverschaffers. Dit betekent dat - onder de veronderstelling van een ongewijzigde rendementseis van de vermogensverschaffers - de op tijdstip $t$ naar verwachting optredende wijzigingen in de cash flows voor de jaren $t+1 \mathrm{t} / \mathrm{m} n$ geheel worden toegerekend aan het gerealiseerde economische rendement voor jaar $t\left(=r(E I)_{t}\right)$, evenals het opgetreden verschil tussen de begrote en de gerealiseerde cash flow voor jaar $\mathbf{t}$.

Bij het administratieve winstbegrip wordt, indien wij ons beperken tot het op historische prijzen gebaseerde winstbegrip, in principe geen wijziging ${ }^{8}$ aangebracht in de - door het afschrijvingssysteem bepaalde - boekwaarde van de materiële vaste activa waarin het vermogen is geinvesteerd. Dit betekent dat de op tijdstip $t$ verwachte wijzigingen in de cash flows voor de jaren $t+1 \mathrm{t} / \mathrm{m} n$ geheel worden toegerekend aan de verwachte administratieve rendementen voor de jaren $t+1 \mathrm{t} / \mathrm{m} \mathrm{n}$ en dat uitsluitend het verschil tussen de begrote en de gerealiseerde cash flow voor jaar $t$ wordt toegerekend aan het gerealiseerde administratieve rendement voor jaar $t\left(=r_{t}\right)$.

Voor een nadere toelichting zie het volgende voorbeeld. 
In aanvulling op de reeds gebruikte symbolen definiëren wij de volgende symbolen:

$$
\begin{aligned}
{ }_{\mathrm{t} C F^{\circ}}(\mathrm{j}+\mathrm{t})= & \text { de op tijdstip } \mathrm{t} \text { begrote cash flow voor jaar } \mathrm{j}+\mathrm{t} ; \\
\mathrm{CF}(\mathrm{t}) & =\text { de in jaar } \mathrm{t} \text { gegenereerde cash flow; } \\
1^{\circ} \mathrm{t} & =\text { de op tijdstip } \mathrm{t} \text { begrote fractie waarmee de cash flows voor de } \\
& \text { jaren } \mathrm{t}+1 \mathrm{t} / \mathrm{m} \text { n naar verwachting zullen stijgen. }
\end{aligned}
$$

De relaties voor de in jaar $t$ gerealiseerde administratieve en economische winst luiden als volgt:

$$
\begin{aligned}
& E(t)=C F(t)-A^{\circ}(t)=C F(t)+B^{\circ}(t)-B^{\circ}(t-1) \\
& E I(O)=V(O)-I \\
& E I(t)=C F(t)+V(t)-V(t-1) \quad(\text { voor } t=1 t / m n) \\
& \text { waarbij V(t) }=\sum_{j=1}^{n-t} \frac{t C F^{\circ}(j+t)}{\left(1+k^{\circ}\right) j}
\end{aligned}
$$

Gegevens$$
\text { I }
$$

$A^{\circ}(t)$

$\mathrm{O}_{\mathrm{CF}}^{\mathrm{CF}(\mathrm{t})}$

1

${ }_{2} \mathrm{CF}^{\circ}(\mathrm{t}+2)$

$\mathrm{CF}(\mathrm{t})$

$\mathrm{l}^{\circ} \mathrm{t}$

Uitwerking

$\mathrm{B}^{\circ}(0)=\mathrm{I}=$

$B^{\circ}(t)=$

$E(t)=$

$\mathbf{r}_{\mathrm{t}}=$

$\mathrm{I}=$

$\mathrm{V}(\mathrm{t})=$

$\mathrm{EI}(\mathrm{t})=$

$\mathbf{r}(\mathrm{EI})_{\mathrm{t}}=$
Einde

jaar 0

900

$\begin{array}{rlc}300 & 300 & 300 \\ 390 & 360 & 330 \\ & 367,20 & 336,60 \\ 397,80 & 367,20 & 336,60 \\ 0,02 & 0 & 0 \\ 0,05 & 0,05 & 0,05\end{array}$

900

$\begin{array}{ccc}600 & 300 & 0 \\ 97,80 & 67,20 & 36,60 \\ 0,109 & 0,112 & 0,122\end{array}$

900

983,026

$655,02 \quad 320,571$

69,794

32,751

0,071
0

16,029

0,05 
Bij de economische winst wordt de op tijdstip $t$ verwachte stijging van de cash flows voor de jaren $t+1 \mathrm{t} / \mathrm{m} n$ geheel toegerekend aan het gerealiseerde economische rendement voor jaar $t$, hetgeen tot uitdrukking komt in de stijging van de waarde van de materiële vaste activa waarin het vermogen is geïnvesteerd per het einde van jaar $t$, welke stijging tevens doorwerkt in de toekomstige waarden van deze activa.

Toegepast op het voorbeeld betekent dit dat:

$$
\mathrm{V}(1)=\left(\frac{367,20}{1,05}+\frac{336,60}{1,05^{2}}\right)=(1,02)(642,177)=655,02
$$

Bij de administratieve winst wordt de op tijdstip $t$ verwachte stijging van de cash flows voor de jaren $t+1 \mathrm{t} / \mathrm{m} \mathrm{n}$ geheel toegerekend aan de verwachte administratieve rendementen voor de jaren $t+1 \mathrm{t} / \mathrm{m} \mathrm{n}$, hetgeen tot uitdrukking komt in de ongewijzigde boekwaarde van de materiële vaste activa waarin het vermogen is geïnvesteerd per het einde van jaar $t$ resp. per het einde van de volgende boekjaren. Dit betekent dat de boekwaarde van deze activa als volgt kan worden weergegeven:

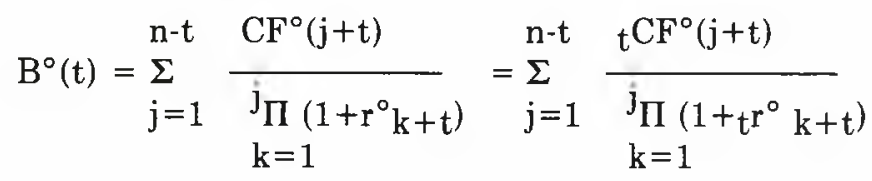

waarbij $\mathrm{tr}^{\circ} \mathrm{k}+\mathrm{t}=$ het op tijdstip $\mathrm{t}$ begrote administratieve rendement voor jaar $\mathrm{k}+\mathrm{t}$.

Toegepast op het voorbeeld betekent dit dat:

$$
\mathrm{B}^{\circ}(1)=\left(\frac{360}{1,10}+\frac{330}{1,10^{2}}\right)=\left(\frac{367,20}{1,112}+\frac{336,60}{(1,112)(1,122)}\right)=600
$$

\section{$3 \mathrm{De}$ - met het oog op de invloed van de in jaar $t$ opgetreden infla- tie - gecorrigeerde nominale resp. reële winst voor jaar $t$}

Zoals wij in paragraaf 2 hebben gezien worden bij de administratieve winst de op tijdstip $t$ naar verwachting optredende wijzigingen in de cash flows voor de jaren $t+1 t / m n$ geheel toegerekend aan de rendementen voor die jaren. Dit betekent dat dit winstbegrip in ongewijzigde vorm geen goed inzicht kan geven in de winstgevendheid van het geinvesteerde vermogen in een situatie met inflatie. De eventueel te ontvangen vergoeding voor het als gevolg van de inflatie in jaar $t$ geleden koopkrachtverlies op het in materiële vaste activa geïnvesteerde vermogen wordt immers slechts gedeeltelijk ontvangen in jaar $t$, namelijk voor zover deze begrepen is in de cash flow voor 
jaar $t$. Het resterende gedeelte wordt eerst via de cash flows voor de jaren $t+1$ $\mathrm{t} / \mathrm{m} \mathrm{n}$ in die jaren ontvangen. Indien wij deze invloed op de cash flows voor de jaren $\mathrm{t}+\mathrm{l} \mathrm{t} / \mathrm{m} \mathrm{n}$ willen toerekenen aan het nominale rendement voor jaar $\mathrm{t}$ en aan de op dit rendement gebaseerde nominale winst voor jaar $t$, dient er een wijziging te worden aangebracht in de boekwaarde van de materiële vaste activa waarin het vermogen is geinvesteerd per het einde van jaar t. Deze boekwaarde vormt immers de schakel tussen de winst voor jaar $t$ en de begrote cash flows voor de jaren $t+1 \mathrm{t} / \mathrm{m} \mathbf{n}$.

Dit betekent dat het nominale rendement voor jaar $t(=r(N) t)$ alsdan zodanig is vastgesteld dat de totale te ontvangen vergoeding voor de in jaar $t$ opgetreden inflatie in dit rendement is verwerkt, zodat hieruit met behulp van het voor het desbetreffende jaar geldende inflatieperuntage $\left(=f_{t}\right)$ rechtstreeks het reële rendement voor jaar $t\left(=r(R)_{t}\right)$ kan worden berekend en wel volgens onderstaande vergelijking.

$r(R)_{t}=\frac{\left(l+r(N)_{t}\right)}{\left(l+f_{t}\right)}-1$

Deze vergelijking 11 betreft in principe de bekende Fisher relatie, met dien verstande dat de Fisher relatie van oorsprong gericht is op de vaststelling van de nominale rendementseis van de verschaffers van (vreemd) vermogen en vergelijking 11 gericht is op de vaststelling van het reële rendement op het in een project geïnvesteerde vermogen. De Fisher relatie wordt in de literatuur veelvuldig toegepast om de samenhang te bepalen tussen nominale en reële opbrengsten- en kostenpercentages (zie bijvoorbeeld B. Carsberg en A. Hope (1976), H. Bierman Jr. (1981) en Y Goldschmidt (1984)).

De in het kader van de nominale winstberekening voor jaar $t$ gecorrigeerde boekwaarde van de materiële vaste activa per het einde van jaar $\mathrm{t}(=\mathrm{B}(\mathrm{t}))$ kan als volgt in een relatie worden weergegeven:

$$
\begin{aligned}
& \mathrm{t} \\
& \Pi\left(1+h^{\circ}{ }_{s}\right) \mathrm{CF}^{\circ}(\mathrm{j}+\mathrm{t})
\end{aligned}
$$

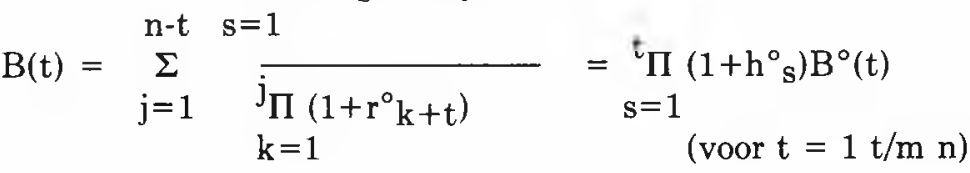

waarbij $h_{S}^{\circ}=$ de fractie waarmee de - door middel van het in materiële vaste activa geïnesteerde vermogen te genereren - cash flows voor de jaren $\mathrm{s}+1 \mathrm{t} / \mathrm{m} \mathrm{n}$ naar verwachting zullen stijgen als gevolg van de in jaar s opgetreden en voor de desbetreffende cash flows relevante nominale prijswijzigingen.

Voor de afleiding van deze relatie verwijzen wij naar het in noot 3 genoemde research memorandum. 
Dit betekent dat de in jaar $t$ vastgestelde nominale winst $(=\mathrm{EN}(\mathrm{t}))$ dan gelijk is aan:

$$
\mathrm{EN}(\mathrm{t})=\mathrm{r}(\mathrm{N})_{t} \mathrm{~B}(\mathrm{t}-\mathrm{l})=\mathrm{CF}(\mathrm{t})+\mathrm{B}(\mathrm{t})-\mathrm{B}(\mathrm{t}-\mathrm{l})
$$

De in jaar $t$ vastgestelde nominale winst is derhalve gelijk aan de in jaar $t$ gerealiseerde cash flow verminderd met het verschil tussen de gecorrigeerde boekwaarde van de materiële vaste activa waarin het vermogen is geïnvesteerd per het einde van jaar $t-1$ en deze boekwaarde per het einde van jaar $t$. In deze nominale winst voor jaar $t$ is derhalve begrepen de naar verwachting in de jaren $t+1 \mathrm{t} / \mathrm{m} \mathrm{n}$ te ontvangen vergoeding voor het als gevolg van de inflatie in jaar $t$ opgetreden koopkrachtverlies op het in materiële activa geïnvesteerde vermogen.

Met behulp van de relatie tussen het nominale en reële rendement voor jaar $t$ (zie vergelijking 11) kan uit vorenvermelde vergelijking voor de nominale winst direct de vergelijking voor de in jaar $t$ vastgestelde reële winst, uitgedrukt in de koopkracht van jaar t-1 $(=\mathrm{ER}(\mathrm{t}))$, worden afgeleid.

$\mathrm{ER}(\mathrm{t})=r(\mathrm{R})_{\mathrm{t}} \mathrm{B}(\mathrm{t}-1)=\frac{\mathrm{EN}(\mathrm{t})-\mathrm{f}_{\mathrm{t}} \mathrm{B}(\mathrm{t}-1)}{\left(1+\mathrm{f}_{\mathrm{t}}\right)}$

De in jaar t vastgestelde reële winst, uitgedrukt in de koopkracht van dat jaar $\left(=\left(l+f_{t}\right) E R(t)\right)$, is derhalve gelijk aan de in jaar $t$ vastgestelde nominale winst verminderd met het inflatieperunage over de boekwaarde van het in materiële vaste activa geïnvesteerde vermogen per het einde van jaar $t-1$. Uit deze reële winst is derhalve de invloed van het als gevolg van de in jaar $t$ opgetreden inflatie geleden koopkrachtverlies op het geïnvesteerde eigen vermogen geëlimineerd.

Het vorenstaande zal aan de hand van een voorbeeld worden toegelicht.

Voorbeeld 2.1

Gegevens

$\begin{array}{llll}\text { Einde } & \text { Einde } & \text { Einde } & \text { Einde } \\ \text { jaar } 0 & \text { jaar } 1 & \text { jaar } 2 & \text { jaar } 3\end{array}$

I

$\mathrm{A}^{\circ}(\mathrm{t})$

$\mathrm{CF}^{\circ}(\mathrm{t})$

$\mathrm{CF}(\mathrm{t})$

$h^{\circ}{ }_{t}$

$\mathrm{f}_{\mathrm{t}}$

Uitwerking

$\mathrm{B}^{\circ}(\mathrm{t})=$

$\mathrm{E}^{\circ}(\mathrm{t})=$

$r^{\circ} t=$
900

\begin{tabular}{lll}
300 & 300 & \multicolumn{1}{l}{300} \\
390 & 360 & \multicolumn{1}{l}{330} \\
409,50 & 400,68 & 381,98 \\
0,05 & 0,06 & 0,04 \\
0,05 & 0,06 & 0,04
\end{tabular}

900

600
90

0,10
300

60

0,10
0

30

0,10 


\begin{tabular}{|c|c|c|c|c|}
\hline $\mathrm{B}(\mathrm{t})=$ & 900 & 630 & 333,90 & 0 \\
\hline$E N(t)=$ & & 139,50 & 104,58 & 48,08 \\
\hline $\mathrm{ER}(\mathrm{t})=$ & & 90 & 63 & 33,388 \\
\hline $\mathrm{r}(\mathrm{N})_{\mathrm{t}}=$ & & 0,155 & 0,166 & 0,144 \\
\hline $\mathrm{r}(\mathrm{R})_{\mathrm{t}}=$ & & 0,10 & 0,10 & 0,10 \\
\hline
\end{tabular}

De gecorrigeerde boekwaarde van de materiële vaste activa per het einde van jaar 1 kan met behulp van vergelijking 12 als volgt worden weergegeven:

$\mathrm{B}(1)=(1,05)(600)=\frac{378}{1,10}+\frac{346,50}{1,10^{2}}=630$

\section{De relatie tussen de in jaar t vastgestelde nominale resp. reële winst en de op actuele waarde gebaseerde winst voor jaar $t$}

In deze paragraaf zullen wij nagaan welke relatie er kan worden gelegd tussen de in jaar $t$ vastgestelde nominale resp. reële winst - zoals deze zijn afgeleid in paragraaf 3 - en de op actuele waarde gebaseerde winst voor jaar $\mathrm{t}(=\mathrm{EA}(\mathrm{t}))$. Laatstgenoemde winst definiëren wij als het verschil tussen de in jaar $\mathbf{t}$ gerealiseerde cash flow en de op basis van actuele waarde vastgestelde afschrijving voor jaar $t(=\mathrm{AA}(\mathrm{t}))$, waarbij ervan uitgegaan wordt dat:

- bij de bepaling van de op actuele waarde gebaseerde winst hetzelfde afschrijvingssysteem wordt toegepast als bij de begrote administratieve winst, zij het dat de prijsgrondslag thans betreft de actuele aanschaffingsprijzen van de materiële vaste activa waarin het vermogen is geïnvesteerd en niet de historische prijzen;

- de aanschaffingsprijs van de desbetreffende activa in jaar $t$ (voor $t=1 \mathrm{t} / \mathrm{m}$ $\mathrm{n}$ ) is gestegen met de fractie $\mathrm{gt}_{\mathrm{t}}$.

Wij geven allereerst de vergelijkingen voor de nominale resp. reële winst voor jaar $t$, alsmede de - op basis van de in deze paragraaf genoemde definitie vastgestelde - vergelijking voor de winst op basis van actuele waarde voor jaar t:

$\mathrm{EN}(\mathrm{t})=\mathrm{CF}(\mathrm{t})+\mathrm{B}(\mathrm{t})-\mathrm{B}(\mathrm{t}-1)$

$\left(l+f_{t}\right) E R(t)=E N(t)-f_{t} B(t-1)$

$\mathrm{EA}(\mathrm{t})=\mathrm{CF}(\mathrm{t})-\mathrm{AA}(\mathrm{t})=\mathrm{CF}(\mathrm{t})+\mathrm{BA}(\mathrm{t})-\left(1+\mathrm{g}_{\mathrm{t}}\right) \mathrm{BA}(\mathrm{t}-1)$

waarbij $\mathrm{BA}(\mathrm{t})$ = de op actuele waarde gebaseerde boekwaarde van de materiële vaste activa per het einde van jaar $t$.

Uit de vergelijkingen 15 en 17 volgt dat: 


$$
\begin{aligned}
& \mathrm{EN}(\mathrm{t})-\mathrm{EA}(\mathrm{t})=\mathrm{B}(\mathrm{t})-\mathrm{BA}(\mathrm{t})-\mathrm{B}(\mathrm{t}-1)+\mathrm{BA}(\mathrm{t}-\mathrm{l})+\mathrm{g}_{\mathrm{t}} \mathrm{BA}(\mathrm{t}-1) \\
& \begin{array}{rlrl}
\text { waarbij } B(t)= & \prod_{s=1}^{t}\left(1+h^{\circ}{ }_{s}\right) B^{\circ}(t) & (\text { voor } t=1 t / m n) ; \\
& t & & \\
B A(t) & =\prod_{s=1}\left(1+g_{s}\right) B^{\circ}(t) & (\text { voor } t=l t / m n) .
\end{array}
\end{aligned}
$$

Het vorenstaande betekent dat indien wij veronderstellen, dat:

de in jaar s (voor $\mathrm{s}=1 \mathrm{t} / \mathrm{m} \mathrm{t}$ ) opgetreden prijsstijging van de materiële vaste activa waarin het vermogen is geïnvesteerd gelijk is aan de fractie waarmee de daarmee te genereren cash flows voor de jaren $\mathrm{s}+1 \mathrm{t} / \mathrm{m} \mathrm{n}$ naar verwachting zullen stijgen als gevolg van de in jaar $s$ opgetreden nominale prijswijzigingen, d.w.z.: $\mathrm{g}_{\mathrm{s}}=\mathrm{h}_{\mathrm{S}}^{\circ}$ (voor $\mathrm{s}=\mathrm{lt} / \mathrm{m} \mathrm{t}$ )

de op actuele waarde gebaseerde boekwaarde van de materiële vaste activa per het einde van jaar t gelijk is aan de - ten behoeve van de nominale winstberekening voor jaar $t-$ gecorrigeerde boekwaarde van deze activa.

Vergelijking 18 kan dan worden herschreven als:

$\mathrm{EN}(\mathrm{t})=\mathrm{EA}(\mathrm{t})+\mathrm{gt}_{\mathrm{t}} \mathrm{BA}(\mathrm{t}-1)$

Onder de genoemde veronderstelling is de in jaar t vastgestelde nominale winst derhalve gelijk aan de winst op basis van actuele waarde voor jaar $t$ vermeerderd met de in het desbetreffende jaar plaatsgevonden herwaardering van de materiële vaste activa waarin het vermogen is geïnvesteerd. ${ }^{10}$

Met behulp van de vergelijkingen 16 en 19 kan ook rechtstreeks het verband tussen de in jaar $t$ vastgestelde reële winst en de winst op basis van actuele waarde worden afgeleid.

$$
\left(1+f_{t}\right) E R(t)=E A(t)+g_{t} B A(t-1)-f_{t} B(t-1)
$$

De in jaar t vastgestelde reële winst, uitgedrukt in de koopkracht van dat jaar, is derhalve onder de genoemde veronderstelling gelijk aan de winst op basis van actuele waarde voor jaar $t$ vermeerderd met de in het desbetreffende jaar plaatsgevonden herwaardering van de materiële vaste activa waarin het vermogen is geinvesteerd en verminderd met het inflatiepernuage over de gecorrigeerde boekwaarde van deze activa per het einde van jaar $t-1$.

Indien wij tevens veronderstellen dat:

de in jaar t opgetreden specifieke prijsstijging van de materiële vaste activa gelijk is aan de fractie waarmee het algemene prijspeil in het desbetreffende jaar is gestegen, d.w.z.: $\mathrm{g}_{\mathrm{t}}=\mathrm{f}_{\mathrm{t}}$, volgt uit vergelijking 20 dat:

$\left(1+f_{t}\right) \operatorname{ER}(t)=E A(t)$ 
De in jaar $t$ vastgestelde reële winst, uitgedrukt in de koopkracht van dat jaar, is alsdan gelijk aan de winst op basis van actuele waarde voor jaar $t$.

Het vorenstaande zal aan de hand van onderstaand voorbeeld nader worden geillustreerd. In het in de appendix opgenomen voorbeeld wordt de in jaar $t$ vastgestelde nominale winst vergeleken met de economische winst voor dat jaar.

\section{Voorbeeld 2.2}

Gegevens

$\begin{array}{llll}\text { Einde } & \text { Einde } & \text { Einde } & \text { Einde } \\ \text { jaar } 0 & \text { jaar } 1 & \text { jaar } 2 & \text { jaar } 3\end{array}$

Zie voorbeeld 2.1, alsmede

gt

$0,05 \quad 0,06 \quad 0,04$

Uitwerking

$B(\mathrm{t})=$

$\mathrm{BA}(\mathrm{t})=$

$g_{t} B A(t-1)=$

$\mathrm{AA}(\mathrm{t})=$

$E N(t)=$

$\mathrm{ER}(\mathrm{t})=$

$\mathrm{EA}(\mathrm{t})=$

900

900

Conclusie

1: $\mathrm{EN}(\mathrm{t})-\mathrm{EA}(\mathrm{t})=$

$=\mathrm{g}_{\mathrm{t}} \mathrm{BA}(\mathrm{t}-1)=$

2: $\left(1+f_{t}\right) E R(t)-E A(t)=$
45

0
630

630

45

315

139,50

90

94,50
333,90

333,90

37,80

333,90

104,58

63

66,78

0

0

13,356

347,256

48,08

33,388

34,724

13,356

37,80

0

0

\section{Samenvatting en conclusie}

In dit artikel is ingegaan op de vraag of met behulp van een op actuele waarde gebaseerd winstbegrip een inzicht kan worden verkregen in de winstgevendheid van het geïnvesteerde vermogen in tijden van inflatie en zo ja op welke wijze deze op actuele waarde gebaseerde winst dan dient te worden berekend. Hierbij werd uitgegaan van de vereenvoudigende veronderstellingen dat het vermogen uitsluitend geïnvesteerd is in materiële vaste activa en geheel betrekking heeft op eigen vermogen, terwijl voorts afgezien wordt van de invloed van de winstbelasting. Teneinde deze vraag te kunnen beantwoorden hebben wij een correctiemethode afgeleid om het administratieve op registratieregels gebaseerde - winstbegrip aan te passen met het oog op de invloed van de in jaar t opgetreden inflatie. Wij hebben ons daarbij op de administratieve winst gebaseerd, aangezien de op actuele waarde berekende winst op hetzelfde toerekeningssysteem is gebaseerd als deze administratieve winst.

De winst voor jaar $t$ wordt niet rechtstreeks beinvloed door de in dat jaar opgetreden inflatie. Dit is wel het geval bij de door middel van het in de onderneming geïnesteerde vermogen te genereren cash flows voor de jaren $t$ $\mathrm{t} / \mathrm{m} \mathrm{n}$, welke cash flows - afhankelijk van het gekozen toerekeningssysteem 
- de winst voor jaar $t$ bepalen. Als uitgangspunt voor de afleiding van deze correctiemethode is derhalve gekozen voor de relatie tussen de administratieve winst voor jaar $t$ en de cash flows voor de jaren $t \mathrm{t} / \mathrm{m} n$. De schakel tussen deze winst voor jaar $t$ en de op tijdstip $O$ resp. $t$ begrote cash flows voor de jaren $t+1 \mathrm{t} / \mathrm{m} \mathrm{n}$ wordt onder de hiervoor genoemde veronderstellingen gevormd door de boekwaarde van de materiële vaste activa waarin het vermogen is geïnvesteerd per het einde van jaar t. Dit houdt in dat, indien men de invloed van de in jaar t opgetreden nominale prijswijzigingen op de cash flows voor de jaren $t+1 \mathrm{t} / \mathrm{m} \mathrm{n}$ tot uitdrukking wil laten komen in de nominale winst voor jaar $t$, dit dient te geschieden via een correctie van de boekwaarde van deze activa per het einde van dat jaar.

Bij de op actuele waarde gebaseerde jaarrekening wordt de boekwaarde van de materiële vaste activa jaarlijks gecorrigeerd aan de hand van de in het desbetreffende jaar opgetreden specifieke prijsstijging van deze activa. Onder de veronderstelling dat de in jaar $s$ (voor $s=1 \mathrm{t} / \mathrm{m}$ t) opgetreden specifieke prijsstijging van deze activa gelijk is aan de fractie waarmee de daarmee te genereren cash flows voor de jaren $\mathrm{s}+1 \mathrm{t} / \mathrm{m} \mathrm{n}$ naar verwachting zullen stijgen als gevolg van de in jaar $\mathrm{s}$ opgetreden nominale prijswijzigingen, is deze op actuele waarde gebaseerde boekwaarde van die activa gelijk aan hun in het kader van de nominale winstberekening voor jaar $t$ gecorrigeerde boekwaarde. Dit betekent dat als aan deze veronderstelling is voldaan met behulp van een op actuele waarde gebaseerd winstbegrip een goed inzicht kan worden verkregen in de nominale resp. reële winstgevendheid van het geïnvesteerde vermogen.

Bij de uitwerking van vorenvermelde probleemstelling is - zoals gemeld geabstraheerd van de invloed van het financieren met vreemd vermogen en van het investeren in monetaire activa, alsmede van de invloed van de winstbelasting. De invloed van deze aspecten op de berekening van de op actuele waarde gebaseerde winst komen in een afzonderlijk artikel aan de orde. Dit artikel is voor belangstellenden op aanvraag bij de redactie verkrijgbaar.

\section{Appendix}

Voorbeeld: vaststelling van de nominale resp. economische winst voor jaar $t$ in een situatie met inflatie

$$
\begin{aligned}
& \mathrm{EI}(\mathrm{N})(\mathrm{O})=\mathrm{V}(\mathrm{O})-\mathrm{I} \\
& \mathrm{EI}(\mathrm{N})(\mathrm{t})=\mathrm{CF}(\mathrm{t})+\mathrm{V}(\mathrm{t})-\mathrm{V}(\mathrm{t}-\mathrm{l}) \\
& \mathrm{r}(\mathrm{EI})(\mathrm{N})_{\mathrm{t}}=\mathrm{EI}(\mathrm{N})(\mathrm{t}): \mathrm{V}(\mathrm{t}-\mathrm{l})
\end{aligned}
$$

(voor $\mathrm{t}=1 \mathrm{t} / \mathrm{m} \mathrm{n})$

(voor $t=1 \mathrm{t} / \mathrm{m} \mathrm{n}$ ) 
waarbij $\operatorname{EI}(\mathrm{N})(\mathrm{t})$ = de economische winst voor jaar $\mathrm{t}$ in een situatie met inflatie;

$\mathrm{r}(\mathrm{EI})(\mathrm{N})_{\mathrm{t}}=$ het nominale economische rendement voor jaar $\mathrm{t}$ in een situatie met inflatie;

$\mathrm{V}(\mathrm{t}) \quad=\sum_{j=1}^{\mathrm{n}-\mathrm{t}} \frac{\mathrm{tCF}^{\circ}(\mathrm{j}+\mathrm{t})}{\left(\mathrm{l}+\mathrm{k}(\mathrm{N})^{\circ}\right)^{\mathrm{j}}} \quad($ voor $\mathrm{t}=\mathrm{l} \mathrm{t} / \mathrm{m} \mathrm{n}) ;$

$\mathrm{k}(\mathrm{N})^{\circ} \quad=$ de voor een situatie met inflatie begrote rendementseis van de vermogensverschaffers voor de jaren 1 $\mathrm{t} / \mathrm{m} \mathrm{n}$.

Gegevens

I

$A^{\circ}(t)$

$\mathrm{O}^{\mathrm{CF}}(\mathrm{t})$

$\mathrm{CF}^{\circ}(\mathrm{t}+1)$

$\mathrm{CF}^{\circ}(\mathrm{t}+2)$

${ }^{2} \mathrm{CF}(\mathrm{t})$

$\mathrm{h}^{\circ} \mathrm{t}$

$\mathrm{f}_{\mathrm{t}}$

$\mathrm{k}^{\circ}$

$\mathrm{k}(\mathrm{N})^{\circ}$

Uitwerking

$\mathrm{B}(\mathrm{O})=\mathrm{I}=$

$\mathrm{B}(\mathrm{t})=$

$\mathrm{EN}(\mathrm{t})=$

$\mathrm{r}(\mathrm{N})_{\mathrm{t}}=$

I $=$

$\mathrm{V}(\mathrm{t})=$

$\mathrm{EI}(\mathrm{N})(\mathrm{t})=$

$\mathrm{r}(\mathrm{EI})(\mathrm{N})_{\mathrm{t}}=$

$\begin{array}{llll}\text { Einde } & \text { Einde } & \text { Einde } & \text { Einde } \\ \text { jaar 0 } & \text { jaar 1 } & \text { jaar 2 } & \text { jaar 3 }\end{array}$

900

\begin{tabular}{lll}
300 & 300 & 300 \\
390 & 360 & \multicolumn{1}{l}{330} \\
& 389,37 & 371,20 \\
& & 371,20 \\
405,60 & 389,37 & 371,20 \\
0,04 & 0,04 & 0,04 \\
0,02 & 0,02 & 0,02 \\
0,05 & 0,05 & 0,05 \\
0,071 & 0,071 & 0,071
\end{tabular}

900

$\begin{array}{ccc}624 & 324,48 & 0 \\ 129,60 & 89,85 & 46,72 \\ 0,144 & 0,144 & 0,144\end{array}$

900

983,026

83,026

In de economische winst voor jaar $t$ is tevens verwerkt de invloed van de in de jaren $t+1 \mathrm{t} / \mathrm{m} \mathbf{n}$ optredende nominale prijswijzigingen op de cash flows voor deze jaren, mits deze wijzigingen reeds op tijdstip $t$ worden begroot. Bij de volgens onze correctiemethode vastgestelde nominale winst is dit niet het geval. In deze winst is uitsluitend verwerkt de invloed van de in jaar $t$ opgetreden nominale prijswijzigingen op de cash flows voor de jaren $t \mathrm{t} / \mathrm{m} \mathrm{n}$.

\section{Literatuur}

H. Bierman Jr., Financial management and inflation, The Free Press, New York 1981.

M. Bromwich, The usefulness of current replacement cost information within a general economic decision framework, opgenomen in: J. Klaassen en P. Verburg.

B. Carsberg en A. Hope, Business investment decisions under inflation, The Institute of Chartered Accountants in England and Wales, Londen 1976.

E.O. Edwards en P.W. Bell, The theory and measurement of business income, University of California Press, Berkeley 1961.

Y. Goldschmidt, The usefulness of current replacement cost within an economic decision framework, opgenomen in: J. Klaassen en P. Verburg. 
J. Klaassen en P. Verburg (eds.), Replacement costs for managerial purposes, North-Holland, Amsterdam 1984.

L. Revsine, Replacement cost accounting, Prentice-Hall, Englewood Cliffs 1973.

Prof. Drs. I. van der Zijpp, Aanschafprijzen en vervangingswaarden, Maandblad voor Accountancy en Bedrijfshuishoudkunde, oktober 1984.

Noten

1 De actuele waarde van de materiële en financiële vaste activa en van de materiële vlottende activa betreft in principe de vervangingswaarde, doch kan ook betreffen de bedrijfswaarde of de opbrengstwaarde.

2 De gerealiseerde herwaardering betreft in principe het verschil tussen de bedragen voor afschrijvingen en goederenverbruik berekend op basis van vervangingswaarde en die berekend op basis van historische prijzen.

3 Een uitgebreide versie van deze twee artikelen is opgenomen in mijn research memorandum getiteld: 'De betekenis van een op actuele waarde gebaseerd winstbegrip bij de bepaling der winstgevendheid van het geinvesteerde vermogen in tijden van inflatie'. Hierin zijn o.m. opgenomen de afleidingen van de in deze twee artikelen opgenomen cash flow relaties.

$4 \mathrm{De}$ in dit artikel af te leiden conclusies gelden ook indien de investeringsuitgave betrekking heeft op materiële vlottende activa.

5 De onderneming kan worden beschouwd als een verzameling van $m$ projecten.

6 Indien het vermogen tevens is geinvesteerd in materiele vlottende activa komt deze toerekening mede tot uitdrukking in het gehanteerde systeem van voorraadwaardering, welk systeem in principe tevens de boekwaarde van deze activa bepaalt.

7 In de cash flow voor jaar $n$ is tevens begrepen de eventuele restwaarde aan het einde van jaar $n$ van de materiële vaste activa waarin het vermogen is geinvesteerd.

8 Een uitzondering hierop betreft de vorming van een voorziening, als gevolg waarvan een op tijdstip $t$ verwachte daling van de cash flow voor een toekomstig jaar resp. jaren wordt toegerekend aan het rendement voor jaar $t$.

9 Voor de beantwoording van de vraag onder welke voorwaarden de specifieke prijsstijging van de materiële activa in jaar $t$ de fractie benadert waarmee de cash flows voor de jaren $t+l t / m n$ naar verwachting zullen stijgen als gevolg van in jaar $t$ opgetreden prijswijzigingen: zie o.m. Reusine (1973) en Bromwich (1984).

10 In de literatuur komt men deze conclusie - zij het vanuit een andere uitgangssituatie bereikt - o.m. tegen bij Edwards en Bell (1961) en van der Zijpp (1984). 